Versión del francés realizada por:

JULIA InÉs LANDAZÁBAL Q.

Profesora Asociada Universidad Pedagógica Nacional

María CRistina Melo R.

Profesora Titular Universidad Pedagógica Nacional

\title{
OPCIONES ÉTICAS EN EDUCACIÓN ESPECIAL ${ }^{1}$
}

\author{
JeAN-JACQues Detraux
}

\section{Introducción}

Hoy, más que nunca, es perentorio plantear la problemática de la ética o más exactamente de las opciones éticas a propósito de la educación. Tal como lo dice Fourez (1990), los múltiples movimientos que han atravesado y atraviesan hoy nuestro sistema educativo muestran los riesgos unidos a su 'eficacia'. Tales riesgos no son sólo los de una institución educativa particular, sino los de una sociedad en su conjunto. Por tal razón, los debates a propósito de opciones posibles, de responsabilidades, de límites, y además de la influencia que ejerce el educador profesional sobre el niño, deben multiplicarse y hacerse públicos con todos los ciudadanos y no sólo a puerta cerrada con los especialistas.

\footnotetext{
1 DETRAUX, Jean-Jacques. "Choix éthiques en éducation spécialisée”. EN: Education Spécialisée. Recherches et pistes d'action. Collection Perspectives en Éducation. Traducido y publicado con la autorización de los editores: Extrait de Lepot. Ed. De Boeck Université. Bruxelles, 1996:169-189.
}

Más urgente aún, a nuestros ojos, es la absoluta necesidad de reflexionar sobre el sentido de nuestras prácticas en materia de educación especial. En efecto, no sólo no se ha establecido la legitimidad de la educación especial tal como ésta se realiza en el seno de las instituciones especiales -puesto que ha sido cuestionada por las corrientes ideológicas que predican la integración de las personas con alguna deficiencia-, sino más aún, el educador especial (con frecuencia tomado como tal por el simple hecho de encontrarse en una institución llamada a sí misma como 'especial') parece alejado de los grandes debates que se realizan a propósito de la educación. Ahora bien, para ese educador las opciones son tan cruciales que la sociedad occidental, que invierte amplios recursos financieros para (re)educar a los jóvenes con deficiencia, no los acoge completamente en su seno reconociéndolos totalmente como ciudadanos. Marquet (1991) muestra cómo se oponen dos lógicas contradictorias: por una parte, se trata de favorecer la integración de la persona con discapacidad pero por otra, se busca evitar su nacimiento por todos los medios. 


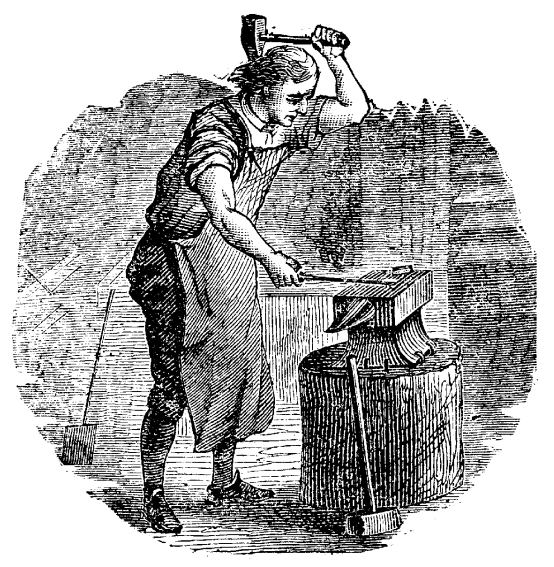

Ciertamente se han hecho reflexiones esenciales en cuanto a bioética, a propósito por ejemplo del derecho a la vida de los fetos que presenten malformaciones; o más aún en relación con la terapéutica respecto a los recién nacidos y que da lugar a la supervivencia de niños con problemas, algunos de estos bastante severos. Sin embargo, como lo recalca Durand (1991), las cuestiones de orden ético, en relación con la discapacidad, pueden parecer secundarias en comparación con aquellas valoradas hoy, gracias al desarrollo de la investigación biomédica.

Bajo el impulso de diversos organismos (entre ellos la ONU) y de diversos movimientos internacionales, la cuestión de una solidaridad necesaria entre todos los seres humanos, el respeto a la diferencia y más recientemente, la atención prestada a la calidad de vida de las personas (por ejemplo en el marco de los cuidados a los moribundos) se han impuesto como temas dominantes que atañen a las intervenciones en el dominio de la educación. El conjunto de estos discursos se centra, primero que todo, en el interés de la persona frente a situaciones de vida ya sean banales o particulares.

En materia de educación especial, sólo recientemente existe la preocupación por pensar en términos de calidad de vida (ver Shallock y col., 1990). Pues bien, múltiples factores contribuyen a la percepción que tienen las personas implicadas, en cuanto a aquello conocido como una 'mejor calidad de vida'.

Convencido del compromiso de 'ayudar' a las personas con discapacidad, el educador tiende a olvidar que, por ejemplo, la prioridad dada a tal o cual tratamiento terapéutico, o las decisiones en cuanto a la orientación del niño dentro de un sistema educativo, o más aún la construcción de un ambiente de informática muy sofisticada alrededor del niño, son actos potencialmente violentos, que pueden atentar contra la dignidad de la 'persona' con discapacidad, aunque aquellos sean puestos en práctica con las mejores intenciones del mundo. La obra de Tomkiewicz y Vivet (1991) denuncia esta violencia.

Nos ha parecido útil contribuir a la reflexión sobre las opciones éticas, realizadas o por realizarse, a propósito de la persona a quien se le atribuye una discapacidad.

Hacer que ella exista como persona (según la intención proclamada en 1981, año internacional de la persona con discapacidad) supone considerar ante todo la relación que cada uno de nosotros puede construir con ella. Será necesario examinar el concepto mismo de 'especial' y cuestionarlo a la luz de corrientes ideológicas actuales. Trataremos finalmente de examinar algunos problemas que se plantean al educador en dos situaciones particulares: en el trabajo con niños pequeños por una parte, y por otra en la intervención en el caso de multi-impedidos severos o situaciones extremas de discapacidad por otra. Como corresponde hacerlo en temas sobre ética, dejaremos el debate abierto pero insistimos por su continuidad en todas las manifestaciones o escritos que tengan que ver con la educación llamada 'especial'. Creemos compartir la posición defendida por Badiou (1993) quien, al criticar radicalmente la ideología ética y sus vertientes sociales -doctrina de los Derechos del hombre, bioética, ética de las diferencias-, propone relacionar la palabra ética con situaciones y procedimientos específicos.

\section{La relación educativa en educación especial}

Más allá de los debates sobre el concepto de educación, conviene subrayar que el acto educati-

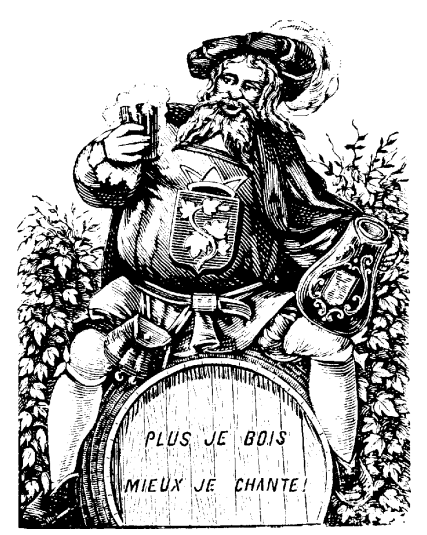


vo supone siempre el establecimiento de una relación entre, por lo menos, dos personas. Consideramos además que la unidad de la relación educativa es una relación dual entre un 'maestro' y un 'aprendiz'. Por lo general, se trata de un adulto y un niño: así, en el encuentro existe ya, a priori, una desigualdad. La educación supone también una restricción: el adulto que ejerce como educador toma la iniciativa, propone e incluso impone, siempre que así lo desee, concientemente o no, sobre el comportamiento y las formas de pensar del niño.

Naturalmente, se trata de utilizar el término educar no sólo en el sentido de la acción orientada del adulto hacia el niño: en efecto, el niño 'se educa' también a sí mismo al confrontarse con situaciones diversas. En este sentido, la institución en tanto sistema es un lugar de aprendizaje en sí mismo. Además, el comportamiento del niño puede también modificar al del adulto en un proceso circular.

Precisemos además que, según nuestro parecer, es educadora toda persona que interviene en relación con el niño en un contexto particular y dotado de un simbolismo propio (el instituto médico-pedagógico, la escuela, etc... pero también la familia). Más tarde haremos la distinción entre relación pedagógica y relación terapéutica, que responden a dos proyectos diferentes aunque potencialmente complementarios. Sin embargo, todos los profesionales comprometidos en una u otra forma de relación son educadores, según nuestro concepto.
Igualmente seguiremos el pensamiento de Fourez (1990) en cuanto muestra el estrecho margen que existe entre el hecho de influenciar al niño y el deseo (o el no-deseo) de hacerlo. De nuestra parte, abogamos por una ética de lo explícito, que finalice en un verdadero contrato entre los actores del proceso de educación; para lograrlo, el educador debe, en todo momento, explicitar su intención frente a su 'aprendiz'. Cuanto más difícil es clarificar esta intención -que es el caso de numerosas situaciones de intervención educativa especial-, más imperiosa será la obligación de hacerlo. Tratemos de ilustrar este punto de vista aplicado al campo que aquí nos interesa.

La relación que se establece entre un 'maestro' y su 'aprendiz' evoluciona naturalmente hacia la desaparición de la misma, es decir, hacia una autonomía del joven en relación con el adulto. En otras palabras, el aprendiz 'mata' un día a su maestro, se entiende que simbólicamente, y se convierte a su vez en maestro. Esta evolución es natural si cada actor juega su papel de manera efectiva: el maestro debe querer enseñar todo aceptando que el aprendiz, poco a poco, cuestione su saber y se rebele. El aprendiz, por su parte, desea aprender (es decir callarse en un primer momento) y, enseguida, adoptar una posición crítica frente al tema objeto de conocimiento. Es importante anotar que la interacción entre los actores debe permitir la complementariedad: cada uno debe asumir su papel para permitir al compañero que asuma el propio.
Cuando quien aprende es considerado como deficiente, se encuentra en una situación en la cual no puede tomar distancia crítica y oponerse a su maestro; ya sea por falta de capacidades, ya sea por la obligación de desempeñar el papel 'excepcional' de persona con discapacidad, o más frecuentemente por combinación de estas dos limitaciones. Así, la relación educativa en el contexto de la educación especial sufre una distorsión tal, que cada actor es cuestionado en su propia identidad. Se instala un malestar, un maltrato. La historia de este encuentro sufre un tropiezo y la exigencia de un contrato explícito entre el educador y el aprendiz, se hace difícil de satisfacer e incluso imposible de mantener.

Ciertamente, en la educación especial, el maestro no está solo: al contrario, está rodeado de un equipo multidisciplinario. Pero, cuando él debería apelar a este equipo para aclarar su relación con el niño deficiente, observamos con frecuencia una dispersión de la acción educativa en múltiples intervenciones que se yuxtaponen, perdiendo así toda la coherencia que podría darse en conjunto. Así, la situación se complica de manera particular por la dificultad, especialmente, de lograr un lenguaje común entre profesionales de disciplinas diversas. Un trabajo importante debe realizarse al interior de los equipos, para tratar de tomar decisiones orientando la acción educativa de manera coherente. Esta concertación es un verdadero trabajo en sí mismo, cuya realización permite explicitar, ante muchos, los valores y crite- 
rios que pueden servir de orientación para la acción.

El contexto simbólico, a su vez, también es cuestionado; por ejemplo, numerosos maestros se preguntan si conviene hablar de 'escuela' cuando se refieren a la 'escuela especial', donde parece que los alumnos no pueden asimilar las asignaturas tradicionales. Más aún, el educador tiene conciencia de hallarse frente a una situación paradójica: quiere asumir su papel de educador y no puede hacerlo por falta de fundamentación en el sistema. Así, maestros de educación especial -que hayan deseado aplicar estrategias para la toma de iniciativa y de autonomía de sus alumnos adolescentes calificados como 'retardados mentales leves' o 'con problemas emocionales'-, entran en contradicción con la misión que creen haber recibido, cual es hacer a esos jóvenes más conformes con su condición de personas con discapacidad, y que se trataría de mantener en un estado de noadultos, de inmadurez relativa, de irresponsabilidad que justifica la continuidad de un 'tratamiento' al salir del sistema escolar.

Se observa al maestro, integrante de un equipo interdisciplinario, necesitado de puntos de referencia y escindido entre la exigencia de tecnicismo en sus actos y su sensibilidad visceral, entre una práctica que cree legitimada por algunos referentes teóricos-incluso si éstos tienen poco que ver con la realidad cotidiana-, y una práctica fundamentada sobre una vivencia, casi funcional en algunos casos, con el sujeto a quien debe educar. La formación de los profesionales debería tomar en cuenta ese dilema, estas contradicciones.

De hecho, no existe solución aparte de la que el educador puede encontrar en él mismo. Es a él a quien, al final de cuentas, compete decidir sobre cuándo y por qué de tal o cual intervención. Es él quien debe sopesar, en una situación concreta, si la respuesta ante una propuesta del niño es coherente con aquello que había pensado hacer, de acuerdo o no con sus colegas. Él mismo es un agente productor de ética.

Dos reflexiones son necesarias:

La primera tiene que ver con la coherencia que encontramos 0 no entre nuestras intenciones, de una parte, y nuestros actos, de otra; la segunda se relaciona con la legitimidad que podemos atribuir a la diferencia entre un proyecto y su ejecución.

Conviene distinguir las dos reflexiones. En efecto, la primera puede tratarse en un nivel puramente técnico. El análisis de las contradicciones, constatadas continuamente en el funcionamiento del equipo, es a la vez sencillo (en todo caso para un observador externo al equipo) y poco interesante si se limita a este nivel técnico. La segunda reflexión-sobre el porqué de nuestros actos-implica más y exige que nos interroguemos en cuanto a nuestros criterios de percepción de la realidad.

Así, la atención a los padres que acompañan a su hijo, declarado ya como 'especial', puede hacerse según una técnica probada, mezclando hábilmente consideraciones administrativas con ac- titudes de comprensión, simpatía, confianza. Pero el tiempo cuenta y es necesario terminar la entrevista, no sin antes solicitar la colaboración de los padres y comprometiéndose para un próximo encuentro.

El simple análisis de los hechos nos revela la existencia de una contradicción entre lo que sucede durante este primer encuentro y todo el discurso acerca de la indispensable colaboración de los padres en el proyecto educativo. Cómo alcanzar dicha colaboración cuando la conducta del maestro en esa primera entrevista significa: A partir de este momento, déjeme actuar; tal vez usted sepa criar a su hijo, pero en lo que se refiere a su educación, créame, es asunto de profesionales 'especializados'. Todo educador ha podido actuar así en ciertas ocasiones, y aunque siempre puede justificar su conducta, no le faltan nunca razones.

Pero ¿puede considerar su conducta como legítima? Para esta pregunta no existe respuesta única. Al dar la suya, el educador debe reconocer el lugar de sus opciones ideológicas (por ejemplo ¿qué representa para él 'ser discapacitado' en nuestra sociedad?) y sus opciones intelectuales (por ejemplo ¿puede justificarse, científicamente, la separación, si no física por lo menos moral y cultural, del niño de su familia?).

\section{La noción de 'especial' y las ideologías dominantes}

La discapacidad es una noción relativa (esto es bien sabido) 
pero ¿relativa a qué? ¿A un grado de deficiencia más o menos severa? ¿A la función implicada (comunicación, desplazamiento...)? ¿A la notoriedad de la deficiencia, del estigma? ¿A situaciones sociales particulares (situación escolar, fiestas, compras, actividades deportivas), o, especialmente, a la forma de organizar las relaciones interpersonales?

Los discursos (incluidos los discursos científicos) que el profesional tiene 'sobre' (horrible palabra) la persona con discapacidad, hacen poca o ninguna referencia a su percepción, a la manera de vivir la relación con esta persona. Todo sucede como si esta persona, calificada como discapacitada, viviera en otro mundo, como si no pudiera vivir sino de sentimientos ajenos (o que no tuviera sentimientos). Esta posición, una vez adoptada, protege al profesional (que no es discapacitado) y lo autoriza a desarrollar discursos a propósito de aquella persona discapacitada, inclusive discursos del estilo "Es indignante", ellos deben soportar la etiqueta que se les ha asignado... son estigmatizados, excluidos... hay que luchar por su integración, etc.... A este propósito, citemos un párrafo de la obra de Badiou (1993: 24):

El problema es que el respeto por las diferencias, la ética de los derechos del hombre parece definir una identidad!! A partir de allí, respetar las diferencias no se aplica sino en tanto se es razonablemente homogéneo con esta identidad (...). Incluso los inmigrantes de ese país no son, a los ojos de los partidarios de la ética, aceptados como diferentes a menos que sean integrados, si desean la integración (lo cual parecería significar, si desean suprimir lo que los diferencia).

Aunque el autor no hace referencia de manera específica a la problemática de la diferencia en cuanto a la discapacidad, parece que el razonamiento puede aplicarse, hasta cierto punto, a las dificultades que experimenta todo educador para relacionarse con la deficiencia. No olvidemos que ésta remite casi siempre a miedos arcaicos: miedo a la enfermedad, a la pérdida, a la muerte.

En la práctica cotidiana, nos encontramos frente a dos clases de discursos.

a) Un primer discurso predica el asumir la responsabilidad de manera intensiva, la ayuda y la asistencia, la rehabilitación por las terapias y las técnicas educativas especiales. Este discurso se basa en una ideología de la segregación que confunde la necesidad de la persona con su deficiencia, con su 'enfermedad' (Gelinas, 1981). Las corrientes que subyacen a esta ideología son, según el autor, las de la medicalización y de la psicologización a ultranza, todo puesto en evidencia a través de instrumentos científicos o seudo-científicos; aquellos de la categorización y de la institucionalización, que crean un sistema para alimentarse y justificarse a sí mismos. Tal como lo señala SafiliosRothschild (1970), la persona debe aceptar su nuevo estatus de 'persona discapacitada' y comportarse en función del mismo, ante todo 'mejorarse' para justificar la pertinencia de la terapia, pero 'permanecer discapacitado' para sustentar su permanencia en el sistema especial. Agreguemos que, más allá de la persona discapacitada, los padres adquieren a su vez el curioso estatus de 'padres de niño discapacitado' y, ellos también, se supone que se resignan a dicho papel.

b) Otro discurso pregona la emancipación, el derecho a la nosegregación, la 'ubicación' en medio abierto... Ese discurso se basa en una ideología que proclama los cambios en las condiciones de inadaptación (Gelinas, 1981). La necesidad es considerada aquí como si no fuera algo intrínseco a la persona sino que hiciera parte de una co-responsabilidad entre el ambiente humano y material que tiene sus exigencias, sus limitaciones y una persona con deficiencia que tiene sus propios límites. Muchas corrientes han surgido de esta ideología, de las cuales sobre la que más se ha teorizado es ciertamente la de la normalización (confrontar los trabajos de Nirje, Wolfensberger y otros). En esencia, estas corrientes son pretendidamente pragmáticas pero son también normativas, y evitan el análisis del concepto mismo de 'necesidad', con la única referencia de la teoría de Maslow (Detraux, Mercier y col., 1990; Detraux, Di Cuca y col., 1992).

Así, los dos discursos presentan una analogía manifiesta: evitan cuidadosamente dar al 'otro' el 
estatus de persona en su totalidad, es decir, como sujeto que actúa y tiene deseos.

En la mayoría de casos, el profesional habla en nombre del otro y se otorga el derecho a hacerlo porque lo ha declarado 'otro' (o ha aceptado esta denominación). Se trata de una cuestión tautológica y, ciertamente, carente de sentido.

¿Puede imaginarse otra alternativa? Prisioneros de los sistemas institucionales, prisioneros del juego social que consiste en pedir a los educadores profesionales que cambien el destino de un ser sin realizar cambios fundamentales en las normas establecidas, los maestros se ven forzados a adoptar una de las siguientes posiciones: la resignación y el repliegue sobre sí mismo, por una parte, o rebelarse, por la otra.

No haremos juicios de valor sobre la actitud de resignación (no olvidemos las importantes barreras psicológicas que pueden existir entre el sujeto discapacitado y el que no lo es, incluso si este último es un profesional en la materia), pero difícilmente la aceptamos. Pues bien, puesto que no existe totalmente por sí mismo, el educador destruye en el niño toda esperanza de vivir plenamente (pensemos por ejemplo en el discurso de la autonomía: ¿cómo un educador puede pretender llevar a un niño hacia cualquier forma de autonomía si él mismo depende de las directivas, de los horarios, de las formas de funcionamiento, también de los prejuicios?).

De nuestra parte, la rebelión es la vía más adecuada y es esen- cialmente de carácter interior. No se lleva a cabo aisladamente, lo cual da seguridad pero complica el proceso. ¿De dónde puede provenir dicha rebeldía?

A propósito nos referiremos a una conferencia ilustrativa de Saulus (1987) que, en relación con Camus, recordaba el mito de Sisifo quien había sido condenado por los dioses a empujar incesantemente una roca hasta la cima de una montaña, desde donde caía ineludiblemente llevada por su propio peso. Los dioses pensaban, en efecto, que no había castigo más terrible que 'el trabajo inútil y sin esperanza'. Sisifo, convertido en héroe del absurdo, está plenamente conciente de la futilidad de un esfuerzo orientado al fracaso; también dimensiona la inmensidad de su 'castigo' y la contradicción que encierra.

Para Camus, Sisifo es un hombre que se ha rebelado: en efecto, él es consciente de su condición absurda y, a pesar de ello, rehúsa obstinadamente el refugio de la esperanza vana y de la resignación. Asume las contradicciones inherentes a su condición, no las niega sino que las enfrenta y siempre vuelve a comenzar.

Saulus compara la situación de Sisifo con la del educador confrontado a niños discapacitados en situación extrema de discapacidad.

Su reflexión puede extenderse al cuadro más amplio de infancia y adolescencia inadaptada social o intelectualmente.

¿No es absurdo, en efecto, que el educador se encuentre ence- rrado en un sistema institucional del cual percibe, así sea globalmente, los límites y las contradicciones, y aún así crea que va a educar, que hará al individuo más autónomo, que le va a permitir su rehabilitación, etc.?

¿No es absurdo para los profesionales, presentarse, incluso imponerse como los 'padres ideales' de este niño moralmente abandonado por sus padres biológicos, sabiendo a ciencia cierta que ellos no lo son y que jamás podrán asumir dicho papel?

¿No es absurdo hablar de la 'reintegración' del joven mientras el sistema lleva a los profesionales a encerrarse en las cuatro paredes de la institución?

Podemos develar así diversidad de situaciones en las cuales los profesionales continúan su trabajo a como dé lugar, como un malabarista encaramado en una cuerda inexistente y sin atreverse a plantear la pregunta: ¿Es razonable actuar de esta manera?

¿La educación especial aparece como misión imposible o como pura ilusión? Ciertamente no, pero es difícil y exige que cada participante preste una atención particular a los aspectos éticos propios de la relación educativa; esto, especialmente, para evitar la 'violencia' en la institución. Dicha violencia no necesariamente es física o aún verbal. El proceso terapéutico, impuesto por los profesionales, la amplitud y la sistematización de ciertos 'métodos' sin que exista un cuestionamiento permanente por su legitimidad, lleva igualmente a la 


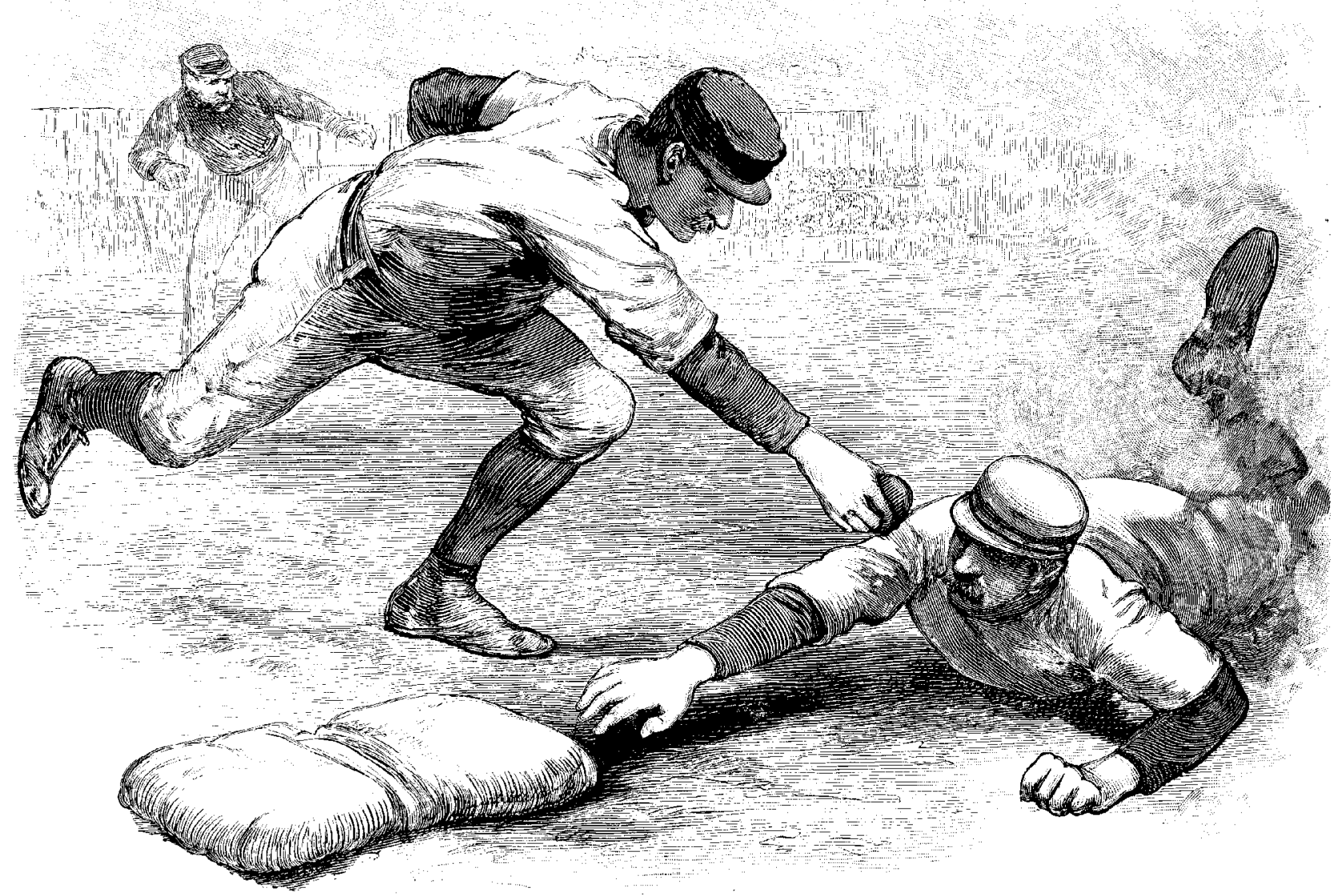

violencia en la institución. Esta puede provocar en ciertos educadores, ya sea un sentimiento de omnipotencia que no admite ninguna contradicción, ya sea un sentimiento de vivencia de fracaso que recae en el joven, convirtiéndose él mismo en fuente de fracaso ( $i e l$ joven no evoluciona porque es discapacitado?).

¿Cómo abordar esta misión en la vida cotidiana? Primero que todo, existen principios aplicables a la organización general de una institución; veremos algunos de manera no exhaustiva.

Puesto que toda institución, es decir, todo sistema, busca un sta- tus quo (fenómeno de la homeostasis), es necesario pues recurrir a la 'utopía'; es decir, una persona o grupo de personas recurre sin cesar al conjunto del sistema, de su existencia y de por qué fue hecho.

Una de las características principales de la educación especial es basarse en el trabajo de equipos multidisciplinarios. La composición multidisciplinaria de un equipo representa una riqueza potencial pero, para que produzca los efectos esperados, es necesario sortear las diferencias de percepción entre quienes intervienen, atendiendo ante todo a crear un lenguaje común. Esta gestión, de la cual es garante el jefe del establecimiento, debe permitir a cada educador hacer una revisión crítica y un análisis de mayor profundidad.

La finalidad de la educación especial es esencialmente ambivalente; como lo hemos enfatizado, el joven busca rehabilitarse pero numerosos elementos exteriores a la institución contribuyen a mantener su situación de discapacitado. Es necesario pues que la institución se abra al exterior $y$, ante todo, al sistema conformado por las familias (es necesario construir un verdadero compañerismo con aquellas reconociéndolas a priori como competentes), e igualmente establecer un trabajo en red con diversos 
servicios, organismos e instituciones relacionadas con el establecimiento educativo. Este trabajo implica que el equipo educativo tenga conciencia de sus propios límites: la institución no puede/ no debe hacer todo, asumir todo. Esto correspondería hacerlo a nivel colectivo, con ese sentimiento de poder al cual nos hemos referido antes.

Existen aspectos particulares en la relación educador-joven, que deben enfatizarse. Dichos aspectos tienen que ver, de una parte, con la existencia de un proyecto a favor del joven $y$, de otra parte, con la mirada de evaluador que recaerá inevitablemente sobre este último.

El proyecto, noción difícil de manejar pues ha sido tergiversada y mal utilizada a propósito de múltiples contextos, representa para nuestros propósitos el conjunto de intenciones y deseos presentes ante todo en el educador, al interior de un equipo y finalmente en el seno de un sistema instituido. El proyecto no se confunde con un escrito. En esencia, el proyecto está siempre por hacerse, es el que impulsa la acción. Es la "vitamina de la praxis" (Barbier, 1977).

Diferenciamos entre 'proyecto pedagógico' y 'proyecto terapéutico'. En el 'proyecto pedagógico', se encuentran intenciones que tienen que ver con la adquisición de un saber determinado, que permitirá al niño conquistar las armas necesarias para su adaptación social y, a partir de ésta, esperar su desarrollo y lograr la autonomía una vez alcanzada la edad adulta. El 'proyecto terapéutico' no busca a priori la adquisición de un saber determinado sino que estimula a un trabajo por y acerca de sí mismo, conduce al individuo a quien beneficia, a transformarse en un plano fisiológico, físico o psicológico, lo cual le permitirá interactuar de manera diferente (en principio de manera más eficaz) con el ambiente.

La distinción entre estas dos formas de proyecto parece inútil a los ojos de algunos, pues se piensa que es obvio que el equipo multidisciplinario forme un todo homogéneo; sería suficiente instaurarlo dentro de un contexto declarado 'especial', para que la acción educativa lo encuentre legítimo.

Pensamos que la distinción entre los dos tipos de proyecto permite que nazca, al interior de los equipos que intervienen, una necesaria dialéctica (y no una oposición) entre aquello que corresponde a una imposición (quiero que asimiles esto) y aquello que pertenece al orden de una apropiación (quiero que hagas algo con lo que encuentras en tu medio y por eso me intereso en tus instrumentos y la forma de utilizarlos). El ideal sería que cada participante, sin perder por ello su identidad profesional, pueda incorporar en su proyecto una parte al menos del proyecto de sus colegas; así podría llevarse a cabo lo que hoy se denomina como aproximación 'transdisciplinaria'.

Por lo demás, aceptamos gustosos la normatividad de los valores y los presupuestos que encierra todo tipo de proyecto. Por esto mismo, ningún participante puede aceptar que el proyecto permanezca implícito. Aclarado esto, es necesario reconocer que es real la dificultad de explicitar el proyecto. Comprometerse en la explicitación del conjunto de las intenciones y expectativas, más o menos específicas, que componen el proyecto en cuestión, es ya de por sí un trabajo. En efecto, éste se alimenta de diversos ingredientes, entre los cuales están las referencias teóricas más o menos 'digeridas', las referencias a las experiencias de vida propias de cada uno (por ejemplo, la manera en la cual el educador reacciona frente a sus propios hijos), un aprendizaje en lo cotidiano (lo que parece 'funcionar' se convierte en proyecto) y buena parte de utopía. Es deseable un acompañamiento al educador para permitirle la formulación y reformulación del proyecto. Se trata de una práctica de honestidad frente al joven y su familia, necesaria para evitar el riesgo de una cuasi-fusión entre el deseo de quien interviene en tanto profesional, y el deseo del otro 'sujeto-objeto' de la intervención educativa. Esta acción permite igualmente que el niño exista no sólo en el presente (formular un proyecto supone un reconocimiento del estado o de la situación en la cual se encuentra el niño), sino también y sobre todo hacia el futuro (para que él pueda crecer y adquirir un día el estatus de adulto).

En este sentido, se trata de relacionar el saber-hacer con el devenir-ser. Lo anterior supone una coherencia en las actitudes educativas; es necesario consagrar tiempo y energía a buscar esta coherencia (de acciones en un momento dado del desarrollo del niño pero también coherencia de 
éstas en el tiempo) que, sin embargo, no será jamás lograda de una manera perfecta. Esta búsqueda de coherencia permitirá inscribir al niño en una historia (la propia) respetando el tiempo (se sabe cuánto puede significar el tiempo, por ejemplo en el caso del niño severamente discapacitado) y el espacio (con frecuencia restringido por el mismo niño en razón de sus limitaciones funcionales).

Se trata de dar, según los hechos, un espacio de libertad al joven, sabiendo que toda vida institucional o toda vida en grupo impone sus limitaciones específicas. Pero sabiendo también que la institución no pertenece propiamente al educador, que ella representa un espacio de vida compartido con el joven.

Algunos podrían imaginar que las opciones éticas del educador revelan sobre todo un 'sentido común'. Pero esto no es suficiente: es necesario que intervengan opciones intelectuales, que se apoyen sobre una argumentación, siempre criticables y susceptibles de ser revisadas pero conformando por el momento el cuadro de referencia que permitirá evitar un estado de fusión con el niño.

A este propósito, conviene recordar lo relacionado con el proceso de evaluación, y las posiciones extremas sobre las cuales puede fundamentarse ésta. Una primera posición es la creencia en un 'objetivismo' absoluto, garantizado por el análisis de las manifestaciones comportamentales. La segunda es el rechazo de toda propuesta de objetivación, y el mantenimiento en un 'subjetivismo' fundamentado sobre la vivencia de una relación intensa con el sujeto.

Cada uno de estos procesos, llevados al extremo, es igualmente ilusorio y peligroso. Los dos vienen a negar la humanidad del individuo y su capacidad de existir aparte del adulto-educador. El proceso correcto consiste, según nosotros, en una síntesis: 'estar implicado sin implicarse'. Sin olvidar a propósito de la evaluación que se está, en tanto profesional, comprometido con unos medios y no con unos resultados. Para analizar toda situación en la cual el niño discapacitado y el adulto-educador se encuentran, es necesario considerar tres niveles de manera simultánea. Ante todo, la realidad del contexto en la cual se mueve el educador, las características materiales de este medio, los comportamientos que presenta cada participante, la manera como esos comportamientos se ajustan los unos a los otros, los modos de interacción. Igualmente, la dimensión simbólica de la relación que se establece entre el adulto y el niño en el contexto particular del centro de recepción, de la escuela, de la familia. En fin, el imaginario de cada sujeto, las representaciones que cada uno hace de los otros, los sentimientos de orden diverso que nacen en él, y aquellos que él presta a los otros.

Subrayemos que el análisis de esos diferentes niveles no se improvisa y que exige en cierto grado el manejo de cuadros teóricos, así como técnicos (por ejemplo técnicas de observación).
Llegamos así a subrayar la necesidad de ser formado como educador, lo mismo que creemos en la necesidad de una separación entre la vida profesional y la vida privada, inclusive si creemos en la complementariedad de esas dos dimensiones de la vida humana.

Además, desconfiaremos evidentemente de una profesionalización excesiva utilizada sólo para lograr compromisos ideológicos.

Esta formación profesional, introducida desde la formación inicial, continúa en el medio laboral y se logra tanto con el niño/adolescente como con los demás miembros del equipo.

La formación continuada debe llevar a la construcción de un lenguaje común que permita una comunicación satisfactoria entre los colegas de la educación. Esta construcción deberá representar en todo caso, una preocupación prioritaria; para ello se hace necesaria la confrontación de las 'percepciones de la realidad' tal como la conciben diferentes compañeros comprometidos en el proyecto.

\section{Algunas problemáticas planteadas en el contexto de dos situaciones particulares}

\subsection{La educación del niño en sus primeros años}

Muchas razones existen para centrarse en ese periodo del desarrollo. 
Si el área que se ha convenido denominar 'ayuda precoz' es relativamente familiar en la mayor parte de los países occidentales, no debe olvidarse que son bien recientes (apenas 15 años) los servicios propuestos para las intervenciones tempranas para los bebes y sus familias. Irónicamente la educación precoz es el fundamento mismo de todo el proceso de la educación especial. En efecto, se sabe cuán determinantes son los primeros años de vida del niño para la construcción del ser. Canevaro (1994) recuerda cómo dicha construcción puede ser difícil para el niño discapacitado cuando éste no puede reconocerse en la realidad total que engloba la deficiencia. Las incapacidades e inadaptaciones que se manifestarán más tarde en el desarrollo, resultan en parte de aprendizajes negativos, inducidos por juicios ('tú no eres eso', 'tú no puedes aquello'). La distorsión que se instaura en las primeras relaciones entre el niño con deficiencia y sus padres, fue en otros tiempos el pretexto de una separación precoz del niño de su familia y su pronta ubicación en un medio especializado, altamente competente en el plano educativo. Los servicios de ayuda precoz introdujeron una ruptura en esa forma de pensamiento, poniendo el acento sobre el aspecto 'natural' de la distorsión (una mujer o un hombre no se deciden fácilmente a ser la madre o el padre de un niño afectado en su integridad física y/o psíquica) así como sobre la existencia de recursos propios, lo cual permite a muchos padres convertirse plenamente en educadores de sus hijos con deficiencia. Se desprende de allí un cuestionamiento de la utilización que los padres pueden hacer de los servicios especializados.

A partir de allí se comprende que las opciones éticas, que tendrán que operarse en el cuadro de las interacciones entre los profesionales de la intervención precoz y la familia, serán esenciales si no se quiere comprometer el proceso de la educación precoz.

Nuestros propósitos se guían por los trabajos del grupo europeo Eurlyaid $^{3}$, en el cual participamos, así como las reflexiones de diversos autores.

Los periodos pre y peri natales, durante los cuales hay especial preocupación por descubrir anomalías en el feto o en el recién nacido, son objeto actualmente de una literatura abundante. Se examinan situaciones críticas tales como: la perspectiva de una eutanasia, posible por los actuales progresos técnicos; el derecho a procrear aún cuando haya riesgos conocidos; la elección depositada en los futuros padres para continuar o no el embarazo (en algunos países se propone evitar la intervención de la seguridad social con aquellos padres que rechazan el aborto terapéutico en caso de malformación conocida en el feto); la posibilidad de dar fin a una reanimación; la calidad de vida del niño que

\footnotetext{
${ }^{3}$ Eurlyaid es un grupo europeo, dirigido por la organización no gubernamental ALEFPA-Europa, que reúne profesionales de la ayuda precoz, padres e investigadores universitarios, provenientes de doce países de la Unión Europea. Los informes de trabajos del grupo están disponibles en la secretaría del CEFES-ULB.
}

va a nacer; la manera como el anuncio de la anomalía se realiza en el medio hospitalario.

Los trabajos del grupo Eurlyaid han demostrado el peligro que encierra convertir en ley la concepción del sufrimiento por parte del profesional, y privar así a los progenitores de la libertad de pensar. En efecto ¿el profesional debe evitar a cualquier precio el sufrimiento (lo cual se debe a un pensamiento materialista que busca suprimir de este mundo toda enfermedad, borrar la muerte) o su único compromiso es manejar el posible contenido de dicho sufrimiento (Van Cutsem, 1992)? Pero la libertad de elección no es posible para los padres sin una completa información y si no se vislumbra un apoyo e inclusive un acompañamiento a largo plazo. Resaltamos, como muchos autores, la importancia de dar la información a la pareja y dejarla que escoja a su propio ritmo. En esta perspectiva, el objetivo de un consejo genético es dar más libertad.

Las primeras relaciones educativas entre el entorno y el niño declarado discapacitado (aún si el diagnóstico, en muchos casos, no ha sido formulado y si lo extraño, lo anormal, no ha sido aún definido) suscitan igualmente muchas preguntas de orden ético.

Así, se cuestiona el derecho que se otorgan los profesionales para intervenir en nombre del interés del niño. El nacimiento de un niño con deficiencia provocará siempre una situación de crisis en el seno familiar, y los padres no podrán sustraerse a la elaboración personal que los lleve a in- 
tegrar en su propia vivencia, de una manera u otra, esta problemática. Ante esta situación puede uno preguntarse ¿En qué medida pueden estos profesionales evadir una ayuda en el plano educativo o terapéutico sin correr el riesgo de ser acusados de 'no ayudar a una persona en peligro'? Por ejemplo, Durand (1991) se pregunta ¿hasta dónde aceptar la libertad de elección de los padres y qué hacer si, con toda evidencia y de manera flagrante, se compromete el interés del niño? ¿No se genera un riesgo perverso, por parte de la colectividad cuando ésta estimula la permanencia en el hogar por razones estrictamente económicas?

Durand continúa: si los padres eligen no ir a una escuela especial sino que buscan la integración en medio regular (guardería, escuela) para su niño con discapacidad, ¿no es legítimo que el responsable de dicha escuela no especializada rechace la inscripción del niño, si los padres no aceptan un acompañamiento terapéutico?

La definición del beneficiario de la intervención precoz, constituye otro punto crítico. En otros términos ¿el niño debe necesariamente hacer progresos $y$, en caso afirmativo para quién? ¿Para sí mismo? ¿Para los padres? ¿Para los profesionales (quienes pueden justificar el gasto aprobado por la colectividad)? Esta pregunta, aparentemente ingenua, tiene en la realidad respuestas diversas, que van desde el rechazo del terapeuta a que los padres participen en su trabajo (se trata de posesionarse del niño considerado como su único cliente), hasta un proyecto de colaboración con los padres, vistos como co-terapeutas, y considerados totalmente como beneficiarios. Los enfoques de inspiración sistémica han reforzado la idea de co-responsabilidad en los progresos, constatados o no, del niño. Pero mal llevados, estos enfoques encierran a veces al niño y a sus padres en un discurso tautológico (todo está en todo) y estéril.

El derecho absoluto que tienen los padres de estar informados sobre todo lo que tenga que ver con el niño, y por lo tanto de recibir todo informe escrito (médico, psicológico, social y otro) con relación a los exámenes o evolución del niño, es objeto de una ardiente polémica. No podemos dejar de subrayar cuán paradójico es, en los profesionales, la posición que afirma simultáneamente que se busca un compartir con los padres pero sin facilitarles los informes de los cuales estos podrían hacer 'un uso inadecuado'.

Es preciso tener en cuenta ciertas reglas deodontológicas en la cuestión, pero nos parece fundamental que el especialista proporcione la información escrita a los padres, redactada de manera que sea comprendida (lo que exige un particular esfuerzo) y utilizar el informe escrito como medio complementario al remitir las conclusiones. Idealmente, esta remisión debería hacerse siempre en el marco de un encuentro personalizado con los padres.

Los anteriores interrogantes, citados a título de ejemplo, muestran que más allá de la afirma- ción de la superioridad del saber científico sobre un saber basado en la experiencia vivida, el profesional difícilmente puede rehusarse a decidir por los padres. Este hecho testimonia la ambivalencia del grupo social con respecto a la anormalidad. Todo sucede como si al rechazar la idea de que los padres de un niño portador de deficiencia sean mejores o peores que otros padres, el grupo social intentará en este primer momento, y a pesar de la afirmación de los valores centrados en la familia, demostrar que no es posible establecer una relación simple y banal con el sujeto en situación de discapacidad y confirma su voluntad de controlar la desviación, la diferencia. Dicho control se concretiza en muchas legislaciones, por una descentralización importante de servicios de intervención especializada y por estimular, e incluso por obligar, a efectuar una intervención en el propio hogar, acentuando así la injerencia en la familia y la dependencia de ésta de un sistema especializado. A veces este proceso puede inscribirse de manera armoniosa dentro del contexto cultural dominante pero, en la mayoría de los países en los cuales hemos estudiado el sistema de intervención temprana, la pregunta queda planteada frecuentemente de manera ambigua.

Encontramos aquí la incapacidad de atribuir un carácter positivo a la presencia del 'diferente'. Sin embargo, muchos padres atestiguan cambios que se han operado en ellos (apertura al otro, atención a detalles del desarrollo, descubrimiento de la riqueza de la comunicación y de sus diversas modalidades, etc.) des- 
pués de haber estado día tras día confrontados a las múltiples manifestaciones de la deficiencia en su niño.

Construir una sociedad que permita un mejor desarrollo para cada uno de sus miembros, pasa por un aprendizaje de este tipo. Dicho aprendizaje no puede hacerse si no es por una verdadera iniciación en la discapacidad y en lo que ella representa (no es exagerado decir que se 'nace' a la deficiencia). Se requiere un proceso voluntario que debe basarse en la explicitación de los valores que guían la elección de alternativas. Pues bien, pensamos que casi todos los días hacemos la economía, en la gestión de lo social, de los debates sobre dichos valores fundamentales.

\subsection{Relación educativa en una situación extrema de discapacidad}

Muy preocupados, desde hace muchos años, por la atención a personas con multi-impedimentos severos, y siendo partícipes desde 1988 de un grupo europeo para el intercambio sobre este tema, nos hemos visto confrontados a múltiples preguntas de orden ético surgidas de la práctica de los educadores. Es evidente que la posición extrema representada por la situación de multi-impedimento, lleva a ampliar cierto número de fenómenos, encontrados con respecto a las personas discapacitadas en general.

Una primera reflexión tiene que ver con nuestra capacidad para reconocer como humano al individuo afectado con deficiencias múltiples y severas. Este reconocimiento permitirá la creación de una relación y dará realmente existencia al otro sujeto. Ante todo los educadores naturales -los padres-, podrán hacerlo respecto a su propio hijo. Para lograrlo, la palabra de los especialistas (médicos, paramédicos, psicólogos) con respecto al niño gravemente discapacitado, va a ser determinante. Con expresiones como 'esta pobre criatura', objeto de múltiples tratamientos, esos profesionales 'autorizan' a los padres a involucrar al niño en el plano afectivo (Van Cutsem, 1992). En términos generales, la mirada positiva en relación con el niño, instaurada en tanto que 'persona', dará un sentido a la acción, confirmará las potencialidades, los límites y sobre todo, la humanidad de ese ser. Para que tal mirada pueda convertirse en positiva plenamente, es imperioso que profesionales y padres vayan tomando conciencia de la representación que poseen (o pueden tener) sobre la situación de discapacidad.

Una vez reconocido como 'niño o adolescente en desarrollo', la persona multi-impedida tiene derecho a la educación y a los cuidados apropiados. Este derecho va acompañado de dos corolarios inmediatos (Saulus, 1993) a saber: de una parte, tomarlo a cargo, aceptarlo, lo cual impide el derecho de las familias a una vida tan normal como sea posible. De otra parte, la obligación de contar con recursos para la educación de la persona discapacitada, sea cual fuere la gravedad de su estado. Es claro que sobre este último punto, las cuestiones de orden ético se mezclan con cuestiones de tipo económi- co o político. Podemos afirmar con certeza que la elección más o menos deliberada de hacer vivir al niño, a pesar de su deficiencia severa y al costo de proezas técnicas, implica automáticamente la obligación de la sociedad de proporcionar los medios para su educación; es decir, permitir a la persona acceder a la más grande autonomía posible y a la capacidad funcional de elegir.

La autonomía es concebida ante todo como la toma de conciencia de unicidad, que permite acceder a una forma de representación de sí mismo. Es además la capacidad de auto gobernarse, de definir la propia norma. Poder elegir no está determinado ipso facto por el grado de autonomía adquirida. Cada uno de nosotros puede permanecer dependiente del medio (situación que viven muchas personas calificadas como discapacitadas) y sin embargo, conservar la capacidad de hacer elecciones entre un conjunto de alternativas. Una consecuencia directa para la relación educativa es la obligación que debe proponerse todo educador de poner constantemente a la persona con discapacidad, en situaciones en las cuales pueda elegir. Se trata de no encerrarla en un discurso 'prisión' en el cual, si la respuesta a la pregunta no es conocida, se confirma su situación de incapacidad. Se trata también de manejar las situaciones de vida de tal manera que sea posible una alternativa real.

Más que con cualquier otra persona, el peligro de violencia está presente en los compromisos que se proponen a la persona 
multi-impedida. Como lo recordábamos antes, esta violencia, de orden individual o institucional, adopta diversas formas: no respeto a la dignidad del individuo confiado al profesional; imposición de un régimen de cuidados y rutinas terapéuticas, sin la posibilidad de oponerse; violación de la intimidad del cuerpo y obligación de moverse en un universo relativamente cerrado.

El riesgo de violencia está unido al agotamiento y a la usura que se instala poco a poco en los profesionales (lo mismo que en los padres). El agotamiento y la usura están relacionados con la gran dependencia de las personas discapacitadas, que dificulta la relación con ellas. También con la dificultad de integrar la duración y la repetición de los cuidados en la percepción que cada educador puede tener del tiempo, de la imposibilidad de encontrar una gratificación y confirmación de su identidad de adulto-educador ante los resultados tan modestos de la acción educativa.

Este riesgo de violencia tiene como consecuencia la obligación de cultivar continuamente la capacidad de los participantes de interactuar con las personas discapacitadas. A dicha obligación se suma la de someter a la mirada de experto, si es posible internacional, todo método 'novedoso' por el cual se manifieste especial interés.

En otros países (Estados Unidos, Canadá) se defiende la idea, y se lleva a la práctica, de la necesidad de un representante de la persona discapacitada, especie de abogado que interviene sin comprometerse afectiva o económicamente, y puede defender también los intereses de la persona en caso de conflicto entre padres y profesionales. No es fácil definir la manera como ese abogado pueda ser escogido, o las competencias que debe reunir. Sin embargo, nuestra reflexión a propósito de una ética de la intervención especial, nos lleva a pensar en la conveniencia de la participación de una tercera persona; su simple presencia puede llevar a plantearse preguntas importantes, en particular cuando la persona discapacitada es adulta y difícilmente se hace respetar como tal. En varios países existe en efecto un estado jurídico llamado de la 'minoría prolongada'. Puede uno preguntarse si la aceptación de un tal estado no constituye la última hipocresía de una sociedad que no ha sabido aceptar la anormalidad.

\section{A manera de conclusión}

Nos parece que sólo una regla debe existir en materia de ética: jamás cerrar un debate y menos aún bajo la forma de una serie de 'recomendaciones' (a excepción, por ejemplo, de recomendaciones de orden metodológico) cuya función sería evitar a cualquier precio la iniciación de un diálogo sobre 'cómo vivir con la anormalidad'.

Esta, difícilmente, puede ser considerada como componente integral de lo humano. Desde hace décadas se ha pensado en numerosos países que la intervención especial, concebida como un conjunto de acciones terapéuticas, re'educativas, rehabili- tadoras, cerrarían el debate sobre la existencia de las 'diferencias' vistas como molestas. Es, gracias al progreso logrado en el campo de la genética, después de presentar las anormalidades como taras incurables y quienes las poseen como si fueran seres peligrosos, como se orientan hoy día hacia la eutanasia, que se pretende racional, preventiva, susceptible de ser utilizada para evitar sufrimientos inútiles. Existe, desafortunadamente una confusión: se trata solamente de financiar el trabajo de hombres vestidos de blanco y encargarlos de organizar nuestros genes, o se trata también de abordar de manera fundamental las formas posibles de relación con las 'desviaciones de la norma'.

Demorándonos un poco en el niño que presenta deficiencias desde el nacimiento y en la persona multi-impedida, sin ocultar nuestra impotencia para enfrentarla, hemos querido presentar situaciones de vida relativamente extremas, en las cuales las decisiones se presentan de manera brutal.

Creemos que no existe discontinuidad entre esas situaciones extremas, minoritarias sobre el plano cuantitativo, y la gran mayoría de situaciones en las cuales han ganado terreno los discursos que pregonan la intervención especial. Las situaciones de educación especial son ante todo hechos de relación educativa; lo anterior significa que son situaciones de confrontación entre dos universos a la vez diferentes y muy próximos: El universo del niño que aprende y el universo de un adulto educador. 
Hemos tratado de mostrar que esta relación educativa no puede reducirse a un acto técnico, aunque sea bien pensado. Esta relación obliga constantemente a diseñar alternativas; los indicios que permitan seguir una u otra vía, no se han escrito en ninguna parte. Están para ser inventados y reinventados. Puede decirse que es el movimiento de esta perpetua creación el que va a legitimar y autenticar el acto educativo.

Pero la educación, ya sea que se lleve a cabo en la familia o en el contexto de la clase, ya sea natural o profesional, no puede ser nunca la preocupación exclusiva del educador. Dicho de otra manera y no es idea original, la educación del niño calificado como discapacitado debe proponerse en los mismos términos de la educación para cualquier niño: ¿Cómo conciliar el máximo desarrollo de la persona y todas las exigencias (incluso las exigencias económicas) de una vida en grupo? Se trata de un debate público, en el cual cada uno debe participar y que no puede reservarse sólo a los iniciados.

\section{BIBLIOGRAFÍA}

Badiou, A. (1993). L'Ethique. Essai sur la conscience du Mal. Paris. Ed. Hatier.

BARBIER, R. (1977). La rechercheaction dans l'institution éducative. Paris. Gauthier-Villars.

Canevaro, A (1994). Discapacidad et parcours d'integration. Revue Européenne du Discapacidad Mental. 1, 1, 19-24.
Detraux, J., J. (1990). Recherche relative aux critères devant présider à la programmation de la capactié d'accueil des établissements et services spécialisés dans le traitement des personnes discapacidadés de la Communauté FranVaise de Belgique. Rapport de Recherche non publié. Bruxelles. CEFES-ULB ET NAMUR: FUNDP.

Detraux J. J., Dı Cuca, M. et coll. (1994). Recherche relative aux besoins des personnes discapacidadées dans la Région de BruxellesCapitale. Phase I-Inventaire des études. Raport non publié. Busxelles. CEFES-ULB.

Durand, B. (1991) Ethique et discapacidad mental de l'enfant. In LENOIR (sous la direction de) N. Lenoir. Aux frontières de la vie: paroles d'éthiques. Paris. La Documentation FranVaise (Collect. De Rapports Officiels).

Fourez, G. (1991) Eduquer: Ecoles, Ethiques, Societés. Bruxelles. Ed. De Boeck (Collect. Pédagogies en développement. Problématiques et recherches.

Gelinas, A. (1991) Analyse critique de l'évolution de l'éducation spécialisée. Québec. Marée Montante (Coopérative d'édition universitaire en Education).

MARQuet, J. (1991) Discapacidad et avortement thérapeutique ou l'impossible intégration. Recherches sociologiques, 22, 1-2, 33-46.

NiRJE, B. (1976) Normalisation e intégration: Concepts de base. In Améliorer la qualité de la vie: un symposium sur les principes de normalisation e d'intégration. Virginia. Airlie House.

Safilios-Rothschild, C. (1970) The sociology and social psychology of disability and rehabilitacion. New York. Random Hoyse.

Saulus, G. (1993). Ethique en matière de polydiscapacidad. Rapport du séminaire européen du groupe d'échanges sur le polydiscapacidad. Bruxelles. Alefpa-Europe.

SAuLus, G. (1987). Prélude absurde: clin d'oeil à Albert Camus. BesanVon. Actes du Colloque A.I.R.

SHALLOCK, R. (Ed.) (1990). Quality of Life Perpsectives and issues. Washington. American Association on Mental Retardation.

Tomkiewicz, S., et Vivet, P. (1991). Aimer mal, châtier bien. Enquêtes sur les violences dans les institutions pour enfants et adolescentes. Paris. Ed. Seuil.

Van Cutsem, V. (1992) Naissance d'un enfant porteur d'un discapacidad: quand les parents et les professionnels se découvrent partenaires. Bruxelles. Ed. De l'AP.

WOLFENSBERGER, W. (1984) La valorisation du rôle social: une nouvelle 'conceptualisation' de la normalisation. Déficience Mentale, 34, 2, 2630. 